MaPan : Jurnal Matematika dan Pembelajaran

p-ISSN: 2354-6883 ; e-ISSN: 2581-172X

Volume 6, No 1, June 2018 (128-137)

DOI: https://doi.org/10.24252/mapan.2018v6n1a12

\title{
PENINGKATAN KEMAMPUAN PEMBUKTIAN MATEMATIS MELALUI MODEL PEMBELAJARAN PROBLEM POSING
}

\author{
Hodiyanto ${ }^{1)}$, Utin Desy Susiaty2) \\ 1,2Program Studi Pend. Matematika IKIP PGRI Pontianak \\ 1,2Jalan Ampera No 88 Pontianak Kalimantan Barat \\ E-mail: hodiyanto@ikippgriptk.ac.id ${ }^{1)}, \underline{\text { d3or4f4ty4@gmail.com }}{ }^{2)}$ \\ Submitted: 30-03-2018, Revised: 26-05-2018, Accepted: 29-05-2018
}

\begin{abstract}
Abstrak:
Hasil penelitian (Hodiyanto, 2017) menunjukkan bahwa kemampuan pembuktian matematis mahasiswa tergolong rendah dan jika hal ini dibiarkan maka berakibat semakin lemahnya kemampuan pembuktian matematis mahasiswa, padahal mahasiswa calon guru tentu akan mendidik dan mengajar siswa/siswinya agar memiliki kemampuan pembuktian matematis yang baik. Oleh sebab itu, peneliti mencoba melakukan penelitian yang bertujuan untuk meningkatkan kemampuan pembuktian matematis melalui penerapan model pembelajaran problem posing. Metode penelitian ini menggunakan metode kuantitatif dengan bentuk penelitiannya berupa penelitian eksperimental semu. Teknik pengumpul data yang digunakan adalah teknik pengukuran dengan alat pengumpul data yang digunakan adalah tes pembuktian matematis. Populasi dalam penelitian ini adalah seluruh mahasiswa semester V Program Studi Pendidikan Matematika IKIP PGRI Pontianak. Teknik pengambilan sampel menggunakan teknik cluster random sampling dan kelas A sore sebagai sampel penelitian. Teknik analisis data dalam penelitian ini menggunakan statistik inferensial, uji t. Hasil penelitian ini menunjukkan bahwa model pembelajaran problem posing dapat meningkatkan kemampuan pembuktian matematis mahasiswa, sehingga secara tidak langsung model pembelajaran problem posing bisa diterapkan untuk peningkatan kemampuan berpikir tingkat tinggi mahasiswa yang levelnya sama dengan kemampuan pembuktian matematis.
\end{abstract}

Kata Kunci: Problem posing, Kemapuan Pembuktian Matematis

\section{DEVELOPMENT OF MATHEMATICAL PROOF ABILITY THROUGH PROBLEM POSING LEARNING MODEL}

\begin{abstract}
:
The results showed that student mathematical proof ability was low (Hodiyanto, 2017) and if this was left without any solution done then mathematical proof ability was the longer the lower when college student will certainly educate and teach students in order to have good mathematical proof ability. Therefore, the researcher tried to develop it through problem posing learning model. This research method used quantitative method, quasi experimental research. Data collecting technique used was a measurement technique and data collection tool used was a mathematical proof test. Population in this research were all student of semester $V$ of mathematic education study program of IKIP PGRI Pontianak. Sampling technique used was cluster random sampling technique and class $A$ afternoon as research sample. Data analysis
\end{abstract}


technique in this research used inferential statistic, $t$ test. The results of this study indicate that the model of learning posing problems affected it, so indirectly the problem posing model could be applied for the development of high-level thinking skills of students with the same level of it.

\section{Keywords: Problem posing, Mathematical Proof Ability}

How to Cite: Hodiyanto \& Utin Desy Susiaty (2018). Peningkatan Kemampuan Pembuktian Matematis Melalui Model Pembelajaran Problem Posing. MaPan : Jurnal Matematika dan Pembelajaran, 6 (1), 130-139.

atematika adalah ilmu yang bersifat deduktif aksiomatif, artinya
rumus maupun teorema diturunkan dari aksioma, definisi maupun
dari teorema sebelumnya yang sudah dibuktikan. Dalam melakukan pembuktian biasanya digunakan metode pembuktian langsung (direct proof) atau pembuktian tidak langsung (indirect proof). Sadikin (2009) mengatakan bahwa bentuk pembuktian langsung di antaranya: metode pengecekan satu persatu, pembuktian dengan eliminasi kasus, dan pembuktian dengan ekuivalensi, sedangkan pembuktian tidak langsung adalah pembuktian dengan cara kontradiksi dan pembuktian dengan cara kontradiksi. Untuk mengaplikasikan metode-metode pembuktian tersebut tentu diperlukan kemampuan pembuktian yang baik. Oleh sebab itu, seseorang yang paham dengan metode pembuktian belum tentu mahir dalam menerapkannya dalam suatu kasus. Tetapi pemahaman terhadap metode pembuktian merupakan langkah awal dalam melakukan pembuktian matematis.

Kemampuan pembuktian matematis adalah salah satu kemampuan yang harus dimiliki oleh mahasiswa calon guru matematika agar mahasiswa mampu untuk berpikir logis dan sistematis. NCTM (Hodiyanto, 2017) disebutkan bahwa mathematical reasoning and proof offer powerful ways of developing and expressing insights about a wide range of phenomena. Lebih lanjut disebutkan bahwa ultimately, a mathematical proof is a formal way of expressing particular kinds of reasoning and justification. Artinya, penalaran dan pembuktian matematis menawarkan cara ampuh untuk mengembangkan dan mengekspresikan wawasan tentang berbagai fenomena. Oleh sebab itu, kemampuan pembuktian matematis adalah cara formal untuk mengekspresikan berbagai fakta atau keterangan dalam penalaran dan pembenaran. 
Menurut Lestari \& Yudhanegara (2015) kemampaun pembuktian matematis adalah kemampuan memahami pernyataan atau simbol matematika serta memberikan alasan/bukti terhadap kebenaran solusi. Pembuktian matematis adalah skematisasi aksioma, konsep dasar dan teorema melalui metode deduktif (Bell, 1976). Knuth, 2002) menyatakan alasan mengapa pembuktian matematika penting untuk dilakukan, diantaranya: untuk memverifikasi bahwa pernyataan itu benar, untuk menjelaskan mengapa pernyataan itu benar, untuk mengomunikasikan pengetahuan matematika, untuk menemukan atau membuat matematika baru, atau untuk mensistematisasi pernyataan ke dalam sistem aksiomatik. Menurut Stylianides, et al. (2007) ada tiga alasan mengapa pembuktian matematika: (1) kemampuan pembuktian sangat penting untuk pembelajaran matematika yang mendalam, (2) kemahiran dalam pembuktian dapat meningkatkan kemampuan matematis mereka lebih luas, dan (3) ditemukannya kesulitan yang dihadapi oleh banyak siswa dan mahasiswa dalam pembuktian matematika.

Berbagai hasil penelitian terdahulu juga menunjukkan bahwa masih banyak mahasiswa yang mengalami kesulitan dalam membuktikan (Selden \& Selden, 2003; Stylianides, Stylianides, \& Philippou, 2007; Ozdemir \& Ovez, 2012; dan Guler, 2016). Selanjutnya hasil penelitian Yerizon (2011) yang menyimpulkan bahwa kemampuan pembuktian matematis mahasiswa masih rendah. Hasil penelitian Hodiyanto (2017) diperoleh bahwa mahasiswa masih banyak melakukan kesalahan dalam melakukan pembuktian matematis khususnya dalam mata kuliah pengantar analisis real. Penelitian ini adalah lanjutan dari penelitian yang dilakukan oleh peneliti yang menyimpulkan bahwa masih banyak mahasiswa yang melakukan kesalahan dalam menyelesaikan soal-soal pembuktian matematis. Oleh sebab itu, perlu dicarikan strategi untuk meningkatkan kemampuan mahasiswa tersebut. Salah satu model yang bisa diterapkan untuk mengatasi masalah di atas adalah model pembelajaram problem posing.

Silver et al. (Siswono, 2008) mengatakan bahwa model pembelajaram problem posing didefinisikan sebagai perumusan soal sederhana atau perumusan ulang soal yang ada dengan beberapa perubahan agar lebih sederhana dan dapat dikuasai. Xia et al. (2008) juga menyatakan bahwa pembelajaran yang melibatkan aktivitas model pembelajaram problem posing dapat menimbulkan ketertarikan peserta didik terhadap matematika, meningkatkan kemampuan mereka dalam mengajukan masalah dan 
meningkatkan kemampuan belajar matematika mereka dengan baik. Cai dan Hwang (Kar \& Isik, 2014) mengatakan "problem posing is defined as the generation of new problem and reformulating an axisting problem" artinya problem posing didefinisikan sebagai pengajuan masalah baru dan merumuskan kembali dari masalah yang ada. Dengan demikian, model pembelajaram problem posing adalah model pembelajaran yang mengharuskan mahasiswa untuk mengajukan pertanyaan-pertanyaan yang lebih sederhana yang mengacu pada penyelesaian soal tersebut, tetapi dalam pembuatan soal/pertanyaan tersebut tentu harus berdasarkan hasil diskusi dengan teman kelompoknya. Setelah pertanyaan dibuat, pertanyaan tersebut akan diserahkan kepada kelompok lain untuk didiskusikan penyelesaiannya. Dalam penyelesaian tersebut mahasiswa harus berdiskusi dengan teman kelompoknya untuk menemukan penyelesaian yang benar. Oleh sebab itu, aktivitas problem posing yang menuntut mahasiswa dalam membuat, menyelesaikan pertanyaan dan berdiskusi atau mengkomunikasikan ide dengan teman kelompoknya akan mampu meningkatkan kemampuan pembuktian matematis mahasiswa.

Silver dan Cai (Mahmudi, 2011) mengklasifikasikan tiga aktivitas koginitif dalam pembuatan soal sebagai berikut: (1) pre-solution posing, yaitu pembuatan soal berdasarkan situasi atau informasi yang diberikan, (2) withinsolution posing, yaitu pembuatan atau formulasi soal yang sedang diselesaikan. Pembuatan soal demikian dimaksudkan sebagai penyederhanaan dari soal yang sedang diselesaikan. Dengan demikian, pembuatan soal demikian akan mendukung penyelesaian soal semula, (3) post-Solution Posing. Strategi ini juga disebut sebagai strategi "find a more challenging problem". Siswa memodifikasi atau merevisi tujuan atau kondisi soal yang telah diselesaikan untuk menghasilkan soal-soal baru yang lebih menantang. Pembuatan soal demikian merujuk pada strategi "what-if-not ...?" atau "what happen if ...".

Beberapa teknik yang dapat digunakan untuk membuat soal dengan strategi itu adalah sebagai berikut: (1) mengubah informasi atau data pada soal semula, (2) menambah informasi atau data pada soal semula, (3) mengubah nilai data yang diberikan, tetapi tetap mempertahankan kondisi atau situasi soal semula, dan (4) mengubah situasi atau kondisi soal semula, tetapi tetap mempertahankan data atau informasi yang ada pada soal semula (Silver dan Cai dalam Mahmudi, 2011). Dalam penelitian ini model pembelajaran problem posing yang digunakan adalh tipe post-solution posing. 
Tujuan dalam penelitian ini adalah untuk mengetahui: (1) kemampuan pembuktian matematis sebelum diajarkan dengan model pembelajaran problem posing. (2) kemampuan pembuktian matematis setelah diajarkan dengan model pembelajaran problem posing. (3) peningkatan kemampuan pembuktian matematis mahasiswa setelah diajarkan dengan model pembelajaran problem posing.

\section{METODE PENELITIAN}

Metode penelitian yang digunakan dalam penelitian ini adalah penelitian kuantitatif dengan bentuk penelitiannya adalah eksperimental semu. Penelitian eksperimen adalah penelitian yang digunakan untuk mencari pengaruh perlakuan tertentu terhadap yang lain dalam kondisi yang dikendalikan (Sugiyono, 2011). Dalam penelitian ini, peneliti ingin mencari peningkatan kemampuan pembuktian matematis melalui penerapan model pembelajaran problem posing.

Populasi penelitian ini adalah seluruh mahasiswa semester V Program Studi Pendidikan Matematika Fakultas Pendidikan MIPA dan Teknologi IKIP PGRI Pontianak dengan pengambilan sampel menggunakan teknik cluster random sampling sesuai dengan metode yang digunakan berupa metode penelitian kuantitatif. Sampel yang diperoleh adalah mahasiswa kelas A Sore semester V Program Studi Pendidikan Matematika.

Teknik pengumpulan data pada penelitian ini menggunakan teknik pengukuran dan komunikasi tidak langsung, sedangkan alat pengumpul data yang digunakan adalah tes pembuktian matematis pada mata kulaih pengantar analisis real. Variabel yang digunakan dalam penelitian ini terdiri dari satu variabel bebas model pembelajaran problem posing dan satu variabel terikat kemampuan pembuktian matematis.

Untuk menjawab tujuan penelitian ketiga, digunakan statistik inferensial uji $t$. Analisis data dengan uji $t$ dilakukan setelah uji prasyarat analisis uji normalitas terpenuhi. Jika kriteria pada uji prasyarat analisis sudah terpenuhi maka dilanjutkan dengan uji t.

Jika data berdistribusi normal, maka dilanjutkan dengan uji-t

$$
\mathrm{t}=\frac{M_{d}}{\sqrt{\frac{\sum x^{2} d}{n(n-1)}}}
$$

Keterangan :

$M_{d}=$ mean dari perbedaan pretest dengan postest

$x_{d}=$ deviasi masing-masing subjek $\left(d-M_{d}\right)$

$\sum x^{2} d=$ jumlah kuadrat deviasi 
$n$ = subjek pada sampel

Arikunto (2006: 275)

Dengan kriteria pengujian :

$H_{0}$ ditolak jika $t_{o b s}>t_{\text {tabel }}$

$H_{0}$ diterima jika $t_{o b s}<t_{\text {tabel }}$

\section{HASIL PENELITIAN DAN PEMBAHASAN}

Hasil penelitian kemampuan pembuktian matematis sebelum dan sesudah diberikan model pembelajaran problem posing ditampilkan pada tabel 1.

Tabel 1. Hasil Penelitian Kemampuan Pembuktian Matematis

\begin{tabular}{lcc}
\hline Kemampuan Pembuktian Matematis & Pretest & Posttest \\
\hline Rerata & 38.47 & 62.24 \\
Standar Deviasi & 12.92 & 18.25 \\
\hline
\end{tabular}

Berdasarkan tabel 1 diperoleh bahwa kemampuan pembuktian matematis mahasiswa sebelum diberikan perlakuan model pembelajaran problem posing tergolong rendah. Hasil pretest yang diperoleh mahasiswa sebelum perlakuan sebesar 38,59 tergolong rendah dan ini menunjukkan bahwa kemampuan pembuktian matematis mahasiswa tergolong rendah sesuai dengan hasil penelitian Hodiyanto (2017) yang menyimpulkan bahwa rendahnya kemampuan mahasiswa dalam menyelesaikan soal pengantar analisis real (soal pembuktian matematis). Setalah diberikan perlakuan dengan model pembelajaran problem posing diperoleh bahwa nilai kemampuan pembuktian matematis sebesar 62,24 .

Untuk melihat pengaruh model pembelajaran problem posing terhadap kemampuan pembuktian matematis dilakukanlah uji statistik inferensial dengan uji t. Tetapi sebelum dilakukan uji $t$, terlebih dahulu dilakukan uji pra syarat uji $\mathrm{t}$ yaitu harus berdistribusi normal baik dari pretest maupu posttest. Hasil uji normalitas dari pretest dan posttest dapat dilihat pada tabel 2.

Tabel 2. Uji Normalitas Pretest dan Posttest

\begin{tabular}{lllll}
\hline Soal & $\boldsymbol{N}$ & $\boldsymbol{L}_{\text {obs }}$ & $\boldsymbol{L}_{a ; n}$ & Keputusan Uji \\
\hline Pretest & 28 & 0,1573 & 0,0167 & $H_{0}$ diterima \\
Posttest & 28 & 0,0856 & 0,0167 & $H_{0}$ diterima \\
\hline
\end{tabular}

Berdasarkan tabel 2 diperoleh bahwa Lobs pretest sebesar 0,1573 dan $L_{o b s}$ posttest sebesar 0,0856 kurang dari $L_{\text {tabel }}$ yaitu 0,0167 yang artinya $\mathrm{H}_{0}$ diterima. 
Oleh sebab itu, dapat disimpulkan bahwa nilai pretest dan posttest kemampuan pembuktian matematis mahasiswa berdistribusi normal, sehingga dapat dilanjutkan dengan uji statistik inferensial, uji t. Hasil perhitungan uji t dapat dilihat pada tabel 3.

Tabel 3. Hasil Uji t Kemampuan Pembuktian Matematis Mahasiswa

\begin{tabular}{llll}
$\begin{array}{l}\text { Kemampuan } \\
\text { Pembuktian Matematis }\end{array}$ & Nilai $\boldsymbol{t}_{\text {obs }}$ & Nilai $\boldsymbol{t}_{\text {tabel }}$ & Keputusan $\boldsymbol{H}_{\mathbf{0}}$ \\
\cline { 2 - 4 } & 12,53 & 2,05 & Ditolak \\
\hline
\end{tabular}

Keterangan: $H_{0}=$ Hipotesis nol

Berdasarkan tabel 3 diperoleh bahwa $t_{\text {obs }}$ sebesar 12,53 dan $t_{\text {tabel }}$ sebesar 2,05 sehingga $t_{o b s}$ terletak di daerah kritis yang artinya $H_{0}$ ditolak dan $H_{a}$ diterima, sehingga dapat disimpulkan bahwa model pembelajaran problem posing berpengaruh terhadap kemampuan pembuktian matematis mahasiwa. Hasil penelitian ini sesuai dengan penelitian yang dilakukan oleh Hodiyanto, Budiyono, \& Slamet, (2016) bahwa model pembelajaran problem posing berpengaruh terhadap kemampuan komunikasi matematis, sehingga kemampuan pembuktian matematis juga dapat dipengaruhi oleh model pembelajaran problem posing karena mahasiswa yang memiliki kemampuan komunikasi yang baik tentu akan mempu menuliskan jawaban dengan versi mereka dengan baik (menulis adalah salah satu indikator dari kemampuan komunikasi matematis) sehingga kemampuan pembuktian matematis mahasiswa juga akan baik, mahasiswa yang memiliki kemampaun pembuktian yang baik tentu akan mampu menuliskan atau mengungkapkan jawaban mereka.

Selain itu, model pembelajaran problem posing berpengaruh terhadap kemampuan pembuktian matematis sesuai dengan pendapat Brown \& Walter, (1993) bahwa memberikan siswa kesempatan untuk mengajukan masalah mereka sendiri dapat menumbuhkan pemikiran yang lebih beragam dan fleksibel, meningkatkan kemampuan memecahkan masalah, memperluas persepsi mereka tentang matematika, sehingga kemampuan pembuktian matematis mereka juga akan meningkat. English (1999) pengalaman dalam pengajuan soal mengakibatkan mahasiswa dapat memberikan alasan analogi ketika mereka membuat soal yang baru. Berikut ditampilkan perubahan kemampuan pembuktian matematis sebelum dan sesudah dibajarkan dengan model pembelajaran problem posing pada gambar 1 . 


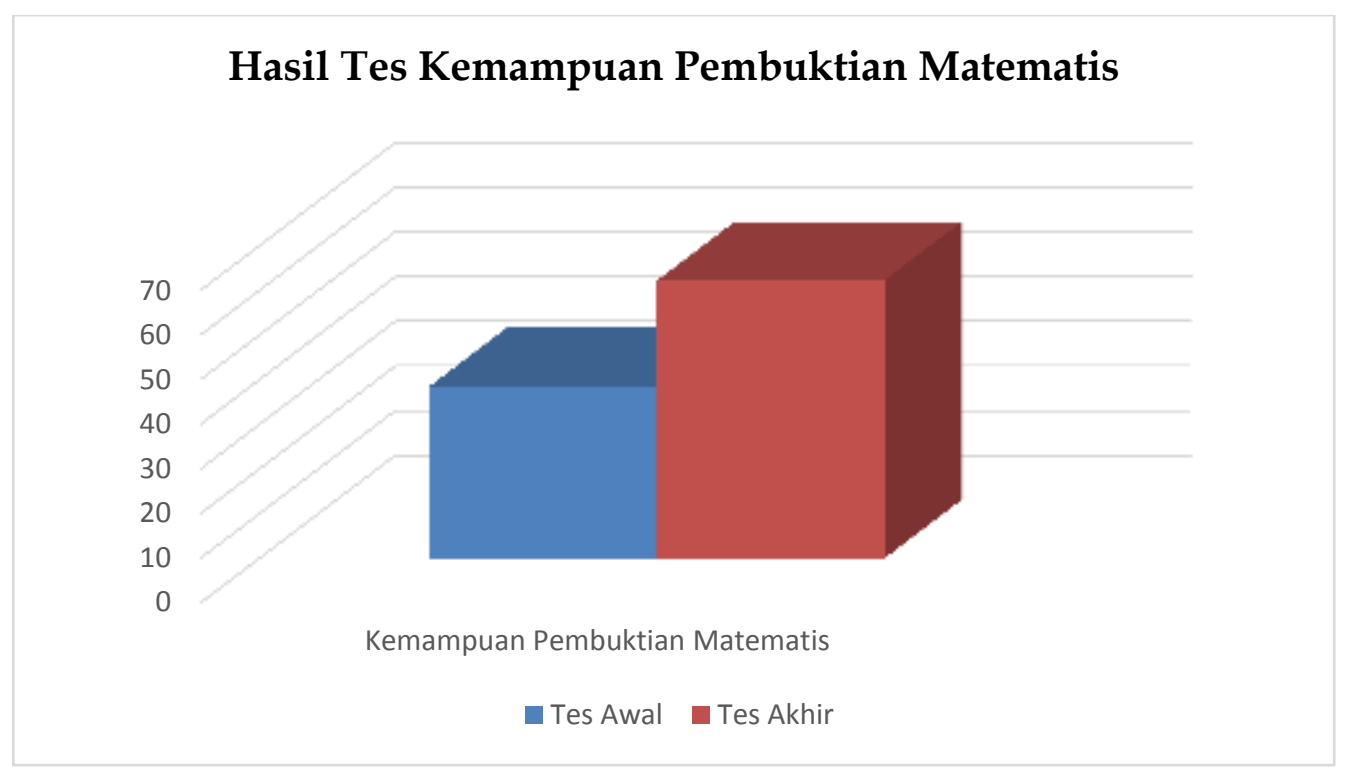

Gambar 1. Grafik Perbandingan Hasil Tes Kemampuan Pembuktian Matematis Mahasiswa

Berdasarkan gambar 1, dapat dilihat bahwa terdapat peningkatan kemampuan pembuktian matematis maahasiswa sebelum dan sesudah diajarkan dengan model pembelajaran problem posing. Sebelum diajarkan dengan model pembelajaran problem posing kemampuan pembuktian matematis mahasiswa sebesar 38,59 tergolong rendah, tetapi setelah diajarkan dengan model pembelajaran problem posing kemampuan pembuktian matematis mahasiswa sebesar 62,24 dan terdapat peningkatan 23,65.

\section{SIMPULAN}

Berdasarkan hasil penelitian dan pembahasan maka dapat disimpulkan bahwa model pembelajaran problem posing berpengaruh terhadap kemampuan pembuktian matematis mahasiswa, sehingga secara tidak langsung model pembelajaran problem posing bisa diterapkan untuk pengembangan kemampuan berpikir tingkat tinggi mahasiswa yang levelnya sama dengan kemampuan pembuktian matematis. Selain itu, penelitian ini juga perlu dilanjutkan oleh penelitian berikutnya dengan mengembangkan model pembelajaran problem posing, misalnya soal yang diajukan berupa open ended. Peneliti berikutnya juga dapat melihat pengaruh lain yang dapat mempengaruhi kemampuan pembuktian matematis, seperti kemandirian belajar, kreativitas, dan habit of mind. 


\section{DAFTAR PUSTAKA}

Arikunto, S. (2006). Prosedur penelitian suatu pendekatan praktik. Jakarta: Rineka Cipta.

Bell, A. (1976). A study of pupils' proof-explanations in mathematical situation. Educational Studies in Mathematics, 7 (1-2), 23-40. http://dx.doi.org/10.1007/BF00144356

Brown, S. I., \& Walter, M. I. (1993). Problem posing in mathematics education. Problem Posing: Reflection and Applications, Hillsdale, New Jersey: Lawrence Erlbaum Associates, 16-27.

English, L. D. (1999). Reasoning by analogy: A fundamental process in children's mathematical learning. Developing mathematical reasoning in grades $\mathrm{K}-12,22-36$.

Lestari, K. E. dan Yudhanegara, M. R. (2015). Penelitian pendidikan matematika. Bandung: PT Refika Aditama.

Guler, G. (2016). The difficulties experienced in teaching proof to prospective mathematics teachers: Academician views. Higher Education Studies, 6 (1), 145.

Hodiyanto, H., Budiyono, B., \& Slamet, I. (2016). Eksperimentasi model pembelajaran problem posing dan problem solving dengan pendekatan pmr terhadap prestasi belajar dan kemampuan komunikasi matematis ditinjau dari kreativitas siswa kelas VII SMP Negeri di Kabupaten Sukoharjo. Jurnal Pembelajaran Matematika, 4 (2), 199-214.

Hodiyanto, H. (2017). Analisis kesalahan mahasiswa semester $\mathrm{v}$ dalam mengerjakan soal pengantar analisis real. Edu Sains: Jurnal Pendidikan Sains \& Matematika, 5 (1), 33-44.

Kar, T. \& Isik, C. (2014). Analysis of problem posed by pre-service primary teachers about adding fraction in termof semantic structure. Internationl Society of Educatinal Research. 9 (2), 135-146.

Knuth, E. J. (2002). Secondary school mathematics teachers' conceptions of proof. Journal for research in mathematics education, 33 (5), 379-405. 
Mahmudi, A. (2011). Problem posing untuk menilai prestasi belajar matematika. Seminar Nasional Matematika Dan Pendidikan Matematika pp. 20-29. UNY: Yogyakarta.

Ozdemir, E. \& Ovez, F. T. D. (2012). A research on proof perceptions and attitudes towards proof and proving: some implications for elementary mathematics prospective teachers. Procedia-Social and Behavioral Sciences, $46,2121-2125$.

Sadikin, A. (2009). Pengantar logika matematika dan himpunan. Pontianak: STAIN Pontianak Press.

Selden, A \& Selden, T. (2003). Validations of proofs considered as texts: can undergraduates tell whether an argument proves a theorem? Journal for Research in Mathematics Education, 34 (1), 4-36.

Siswono, T. Y. E. (2008). Model pembelajaran matematika berbasis pengajuan dan pemecahan masalah untuk meningkatkan kemampuan berpikir kreatif. Surabaya: Unesa University Press.

Stylianides, G. J., Stylianides, A. J., \& Philippou, G. N. (2007). Preservice teachers' knowledge of proof by mathematical induction. Journal of Mathematics Teacher Education, 10 (3), 145-166. 